\title{
The psychological significance of play with imaginary companions in early childhood
}

\author{
Tracy R. Gleason ${ }^{1}$
}

Published online: 13 July 2017

(C) Psychonomic Society, Inc. 2017

\begin{abstract}
Although social play is common to many species, humans are unique in their ability to extract some of the benefits of social play through imagination. For example, in play with imaginary companions (ICs), children often practice skills that might be useful for later adaptive social, relational, and emotional functioning. While play with ICs does not provide the same immediate feedback that play with real others affords, this imagined, quasisocial context allows children to experiment with or rehearse events that might occur in real relationships. This symbolic enactment of social relationships might afford opportunities to experience not just social situations but all manner of positive and negative emotions in a risk-free way. In addition, children's interactions with real others around their ICs allow for negotiation of social roles in real relationships. ICs also provide a forum for psychological distance that might help young children manage their real relationships and engage in processes such as negotiation and cooperation, which are needed for successful social adaptation. Although play with ICs is clearly not of adaptive value in an evolutionary sense, for the children who create them, ICs might hold psychological significance for adaptive social development.
\end{abstract}

Keywords Imaginary companions $\cdot$ Play $\cdot$ Social relationships $\cdot$ Social competence $\cdot$ Psychological distance

Play, particularly in mammals, is often social. Social play episodes consist of individual, specific interactions between

Tracy R. Gleason

tgleason@wellesley.edu

1 Department of Psychology, Wellesley College, 106 Central Street, Wellesley, MA 02481, USA two players and are situated in the larger context of the relationship between the individuals. But what if one of the play partners does not actually exist? Are the psychological and evolutionary advantages of social forms of play relevant when play interactions are only imagined? Certainly, such play is only found in humans, owing to the complex cognition involved in fantasy. But this form of play, specifically, young children's play with imaginary companions, might nevertheless have a significant psychological role in development. Moreover, to the extent that play with imaginary companions shares structural or functional similarities to social play with real partners, it can be compared to and contrasted with the manifestations or functions of social play in other animals. Although such an approach is unlikely to lead to the conclusion that imaginary companions are a significant evolutionary adaptation, it highlights both the uniqueness of this play to humans and emphasizes the importance of social processes, and the play that might facilitate them, common to many species.

Although previous literature has extensively explored the nature and function of social play in myriad species (e.g., Bekoff, 1995; Connolly \& Doyle, 1984; Durand \& Schank, 2015; Pelligrini, 1992; Pellis \& Pellis, 2007), the goal of this article is to demonstrate that, at least for humans, social play is not limited to instances in which multiple partners are present. Instead, the human capacity for imagination provides a context that might afford many of the benefits of true social play. In some ways, an imagined social partner might even be better than a real one since its characteristics can be tailored to a child's needs. Imaginary play partners might also facilitate the development of social competence, particularly with respect to the regulation of emotions and the acquisition of interpersonal skills useful in adulthood, such as cooperation and perspective taking. This mapping of skills from play in childhood to adaptation in adulthood is one way in which play with 
imaginary companions is similar to processes found in other species. Imaginary companions also provide a context for negotiating real social roles and exploring aspects of the social hierarchy as well as a tool for displacing negative emotions from a real to an imaginary relationship. In short, for a species with sufficient cognitive skills, a real play partner is not necessary for social play, and the fact that humans engage in play with imaginary companions reinforces the centrality of relationships to human development.

\section{Imaginary companions}

An imaginary companion (IC) is a character, sometimes invisible and sometimes embodied in an object such as a stuffed animal or doll, which is animated by a child and treated as real. Up to $65 \%$ of children have an IC at some point prior to the age of 7 (Taylor, Carlson, Maring, Gerow, \& Charley, 2004), and many, albeit fewer, children report ICs later in development as well (e.g., Pearson et al., 2001; Taylor, Hulette, \& Dishion, 2010). These creations come in all shapes, sizes, and forms, from humans to animals, spirits, objects, and fantasy creatures (see Table 1 for examples of ICs that I have encountered in my work). They also range in imagined age, gender, and appearance. Often, transitional objects, such as blankets or stuffed animals, evolve over time into so-called personified objects, to which children attribute personality, animation, emotion, and preferences (Gleason, Sebanc, \& Hartup, 2000). Similarly, invisible ICs can be based on fictional characters, real people, or entirely made up. Indeed, the range and variety of the phenomenon runs contrary to the notion that a prototypical IC exists (Taylor \& Carlson, 2002).

The lack of a prototypical IC is part of what makes their psychological significance an intriguing line of inquiry. If ICs fit a single template, an understanding of the psychological significance of children's play with them would have to focus on differences between children who did and did not engage in such play. However, research comparing these groups of children has found much more similarity than distinction. Children with and without ICs do not differ on variables like most personality traits, family structure, number of real friends, or school experience (Gleason et al., 2000; Manosevitz, Prentice, \& Wilson, 1973; Taylor, 1999), although some evidence suggests that children with ICs are more likely than their peers to be firstborn or only children (Gleason et al., 2000; Masih, 1978) and to be sociable (Singer \& Singer, 1990; Taylor, 1999). ICs are also slightly more common in girls than in boys (Carlson \& Taylor, 2005).

Because few differences emerge between children with and without ICs, investigations of ICs' psychological function might instead focus on the characteristics of children's play with them. Some features of pretend friends highlight why this form of play could be significant in children's development, particularly in the social domain. Specifically, ICs often have striking longevity, lasting for months or even years and showing stability in their descriptions (Partington \& Grant, 1984; Taylor, Cartwright, \& Carlson, 1993). ICs are also often incorporated into children's daily routines, becoming, in some instances, an imaginary member of the family (Newson \& Newson, 1968; Taylor, 1999). This persistence, combined with their integration into children's daily lives (Gleason et al., 2000) points to their relevance and importance to the children who create them. In addition, their status as quasirelationship partners has led to scientific inquiry into the ways in which relationships with ICs are both similar to and different from relationships with real partners (Gleason, 2002; Gleason \& Hohmann, 2006).

\section{Imaginary companions as relationship partners}

Conceptualizing ICs in psychological terms as quasirelationship partners might be a reasonable approach for understanding the significance of this form of play. A host of empirical evidence supports this interpretation as well. For example, the desire for a social partner is often cited as the reason why children create ICs (Ames \& Learned, 1946; Gleason et al., 2000; Manosevitz et al., 1973; Svendsen, 1934). In qualitative work, children and parents often describe ICs as distinct others, whose thoughts and behaviors influence their own (Hoff, 2004-2005; Newson \& Newson, 1968), and who are sources of significant emotion (Taylor, 1999). Such interdependence of thoughts, behaviors, and emotions, in conjunction with physical proximity, longevity, and reciprocity across contexts, is what defines real close interpersonal relationships (Kelley et al., 1983), and these features are all imagined in child-IC relationships (Taylor, 1999).

\section{Imaginary relationship variations}

Thinking of ICs as providing relationships for children - albeit imagined ones_-gives a new perspective by which variations in ICs can be understood. At first glance, these relationships would be expected to be idealized. After all, why would a child imagine a relationship that was anything other than idyllic? While some research does suggest that, at least for preschool children, ICs provide forms of social support and relationship benefits that are in line with what the children obtain from best real friends (Gleason, 2002; Gleason \& Hohmann, 2006), ICs are not always stereotyped, "perfect" friends. ICs have been known to frighten children, upset them, cause disappointment and conflict, and disobey them (Taylor, 1999; Taylor, Carlson, \& Shawber, 2007). Some children describe their ICs in terms suggesting that the children do not determine their ICs behaviors, even while acknowledging that 
Table 1 Examples of imaginary companions

\begin{tabular}{ll}
\hline Name & Description \\
\hline $\begin{array}{l}\text { Invisible imaginary companions } \\
\text { Super Muscles }\end{array}$ & An imagined superhero that has large muscles and the power to shrink. \\
Ari & An invisible boy that has his own house, school, family, and birthday. \\
Sunny, Ruby, \& Rosie & Fairies with different-colored hair that fly around the child's room. \\
Ale & An invisible boy who lives on Saturn and has younger twin sisters. \\
Julia & An invisible teenager that has a pet cat and long rainbow-colored hair. \\
$\begin{array}{l}\text { Personified objects } \\
\text { Ariel \& Kennedy }\end{array}$ & Two dolls who do everything that the child does. \\
Lamby & A blanket with a lamb's head who is responsible for any mischief. \\
Asparagus \& Flatomire & Stuffed turtles, who are the child's babies. \\
Chocolate & A stuffed moose, who speaks in a special voice and dislikes peanut butter. \\
Leppy & A stuffed leopard, who is only friends with other cats and speaks Leppy language.
\end{tabular}

the IC is not real (Taylor \& Mottweiler, 2008). Imaginary enemies have even been documented in the literature among typically developing children (Taylor, 1999). These individual differences in relationships with ICs support the idea that these imagined entities function in some way as relationship partners, providing varied types of interaction and possibly even filling specified roles within children's social networks.

Conceptualizing ICs as relationship partners has led to empirical work suggesting that the functional significance of these creations is partly rooted in children's efforts to make sense of relationships and their different structures. By using Weiss's (1974) notion of social "provisions," or characteristics afforded by relationships, Gleason (2002) established that young children associate relationship characteristics with their ICs just as they do with real relationships. Moreover, ICs are related to patterns of provisions in systematic ways. Typically, relationships with ICs are described in terms that make them recognizable as either hierarchical or egalitarian in their organization (Gleason, 2002; Gleason \& Kalpidou, 2014). So whereas ICs themselves seem to exist in every shape, size, and form, limited only by children's imagination, children's relationships with ICs tend to follow systematic, predictable patterns.

\section{Characteristics of relationships with ICs}

Relationship characteristics associated with ICs also appear to relate to their form. Personified objects, for instance, often afford hierarchical relationships, in which the child plays the role of the parent or more competent partner. These objects, whether dolls, stuffed animals, or other objects, thus typically receive extensive nurturance and guidance from children. In contrast, invisible imaginary companions more commonly provide egalitarian relationships akin to friendships (Gleason, 2002; Gleason et al., 2000). Children often describe invisible companions as playmates with whom they share decision making regarding activities and plans. The reasons for these associations between relationship type and IC form are unclear, as is the direction of influence. That is, whether children begin with a particular form of IC (i.e., personified object or invisible) and develop a relationship accordingly, or whether the type of relationship desired by the child prompts gravitation toward a particular form, is unknown.

The distinct patterns found among young children's imagined relationships might be psychologically meaningful, given that, theoretically, relationships with ICs could have any combination of characteristics. Because they are entirely imagined, the features of child-IC relationships could easily be contradictory or inconsistent, or even constantly changing. Why, then, do children create relationships that conform to the patterns of characteristics found in real relationships? Why does one child create an imaginary baby while another creates an imaginary best friend? The fact that these invented relationships are systematic in their organization suggests the hypothesis that the relationship created with an IC might have significance or purpose specific to the child that invents it (Gleason \& White, 2005). Children might thus be choosing the relationship form and type that they seek for their own psychological purposes, tailoring their ICs to provide particular social contexts or social affordances.

\section{ICs as social experience}

The hypothesis that children might construct individualized, imagined social contexts through play with ICs is consistent with Henricks (2015) construction of play as experience. In this view, play is actively sought as a pathway to self-realization, in which various actions are considered and implemented, and then evaluated in terms of their usefulness or appeal to the individual. Similarly, through play, all manner of 
emotion - even negative emotion — can be sought and experienced in a designated context that is more easily regulated than in real life. Vygotsky's (1967) notion of pretend play as providing the zone of proximal development provides the theoretical mechanism by which self-realization is achieved. Within this framework, play with ICs could be conceptualized as a forum for exploring the nature and function of social relationships and their associated emotions, again within the safe confines of the play context. In the imagined relationship with the IC, children experiment and, in a sense, experience, interactions from which they are able to learn and possibly internalize the rules of social relationships. In other words, ICs provide a simulation of a relationship environment, constructed by the child, in which particular interpersonal skills and experiences can be encountered and learned.

This perspective of ICs as a social context invented for exploration of relationship skills and contexts helps explain why some children create ICs who are idealized, and some have ICs whose behavior is difficult at best. Invention of an idealized IC certainly occurs and allows children to enjoy relationship benefits like companionship and validation. For example, a 4-year-old participant in one study created an invisible version of his best friend from school, Danny. The boy's mother described the phenomenon as a function of her child's status as an only child, his affection for the real Danny, and his desire to play with Danny not just at school but as much as possible. She also pointed out, however, that whereas her son and the real Danny had to navigate occasional conflicts in their play, invisible Danny was quick to acquiesce to her son's desires (Gleason et al., 2000). In this case, the IC behaved in ways consistent with what we might expect from invented relationships, including unconditional acceptance and limitless flexibility. While the goal of this imaginary social context appeared to be largely affordance of companionship for an only child, the lack of social effort involved in maintaining the relationship might have been a welcome relief from the work necessary to manage his relationship with his real best friend.

Other children might explore negative aspects of relationships through ICs. Take, for instance, Charlie Ravioli. In an essay in the New Yorker, Adam Gopnik (2002) wrote about his 3 -year-old daughter Olivia's invisible imaginary companion, Charlie Ravioli. Charlie's defining characteristic was his unavailability. Try as she might, Olivia was rarely if ever able to meet up with Charlie, and their missed phone calls and brief interactions on the street were a source of frustration to her. Gopnik explained Olivia's relationship with Charlie in terms of how it reflected the hectic lives of her parents. By creating this dissatisfying relationship, Olivia invented a social context in which to try to understand the circumstances and feelings that accompany a busy schedule in which lengthy social interactions are difficult to achieve - a schedule much like that of her parents.
What this research and these examples suggest is that imagination provides an important venue for young children to consider and explore the nature of social relationships. The psychological significance of this kind of play is highlighted in the choices children make in engagement in these simulated relationships. Children who create ICs, in creating imaginary social relationships, invent social contexts that afford consideration of all manner of interpersonal issues and their associated emotions. By symbolically representing relationships through their ICs, children's preoccupations with particular features of real relationships might be evident at a point in childhood when they are not typically well-articulated (Fraiberg, 1959). Each child might use the IC as a way of mastering a concept or skill that is difficult to manage in reality, but possible to achieve through the abstraction of play (Vygotsky, 1967). Consequently, a child attempting to understand the irreversibility of death might have an IC that dies, and a child trying to understand power dynamics might create an IC that frequently misbehaves and needs significant guidance.

\section{Imaginary companions as a context for social skill development}

Although ICs have not been studied extensively as a social context, some evidence suggests that they might prove useful to children for honing social skills in two ways. First, relationships with ICs - particularly friendships - are a risk-free way of practicing emotion regulation, and, second, much like other forms of play, play with ICs might provide a venue for practice of a large set of interpersonal social skills that foster successful social adaptation in adulthood.

\section{ICs, friendship, and emotion regulation}

Because an imaginary other affords opportunities for all manner of interpersonal experiences, such as nurturance, affiliation, cooperation, empathy, negotiation, and conflict, the child-IC relationship might be a tool for addressing not just the details of interpersonal interaction but for larger tasks of social development (Gleason, 2013). One such task in early childhood is the creation and management of friendship. Unlike relationships encountered earlier in development, primarily within the family, friendship is both egalitarian and open in construction, meaning that neither member of the relationship is inherently more powerful or competent than the other, and either can terminate the relationship at any time (Hartup, 1983). ICs offer a useful opportunity to practice friendship skills in a risk-free way. Anecdotes in the literature detail instances in which children and ICs are inseparable playmates, as well as instances in which an IC rejected the 
child's friendship outright (Newson \& Newson, 1968; Taylor, 1999). Perhaps ICs provide the negative social experiences some children seek to explore without the risks or anxieties inherent in the maintenance of real relationships - especially those like friendship, that are subject to dissolution. What is more, when children's exploration of the social ideas addressed by the ICs are satisfied, these imaginary relationships are easily ended (Kastenbaum \& Fox, 2007-2008).

In cases in which ICs are rejecting, the necessity of coping with such emotional difficulties is a clear theme. Interestingly, differences have been noted between the emotional coping strategies of children with egalitarian ICs and those with hierarchical ones. Children whose ICs provided friendship endorsed coping strategies that were more mature and sophisticated than those of their counterparts whose ICs were subordinate to them (Gleason \& Kalpidou, 2014). These correlational findings do not, of course, suggest that creation of an imaginary friendship results in better emotional coping strategies, but they do suggest a positive relation between simulation of a friendship and these social skills.

Research comparing children with and without ICs also suggests that pretend friends might be implicated in children's efforts to regulate emotions. In comparison to their peers, children with ICs might have a particular focus on social relationships that is tinged with anxiety, at least among school-aged children. For example, children with ICs experience more concentration anxiety than do their peers, meaning that they have greater concerns regarding their ability to meet others' expectations (albeit within a nonclinical range). These concerns are postulated to mean that children with ICs might be particularly attuned to social interactions with others (Bouldin $\&$ Pratt, 2002). This notion is consistent with the greater social anxiety experienced by children with versus without ICs in middle childhood (Shavel-Jessop \& Segal, 2005) and the greater frequency of undergraduate women with dependent interpersonal styles than other styles to remember ICs from childhood (Gleason, Jarudi, \& Cheek, 2003). Taken together, these findings suggest that play with ICs might provide a useful forum for simulating social experiences for individuals who are high on sociability and potentially also preoccupied with their interpersonal relationships - a hypothesis that might underlie individual differences in engagement in this sort of play, particularly after the preschool period.

\section{ICs and social competence}

In addition to the opportunities that ICs afford children for regulating emotion, play with ICs might provide a context for exercise or exploration of other specific behaviors or social skills useful in adulthood. This idea dovetails with much of the research examining connections between play in early life and adaptation in adulthood and is one area in which this form of play can be examined in relation to that of other species. Certainly, studies of human children have established correlations between, for example, engagement in pretend play and enhanced social skills (Connolly \& Doyle, 1984; Taylor \& Carlson, 1997; although, see a review by Lillard et al., 2013, regarding the lack of evidence for a causal relationship), and engagement in rough-and-tumble play and social problem solving (Pelligrini, 1992). Similarly, work in other animals supports the notion of a relationship between playful behaviors in development and cooperation in adulthood (Bekoff, 2001), in part because of the social deficits that emerge when play is thwarted early in development (e.g., Pellis \& Pellis, 2007). This perspective raises the question of whether any skills practiced in interactions with ICs might be used later in development.

In most social forms of play across species, the skills required for the play to start and continue, such as cooperation and reciprocity, are thought to be important in adult social functioning (Durand \& Schank, 2015). In play, individuals must regulate their own behaviors and emotional responses. For instance, overly aggressive attacks in rough-and-tumble play or unmanageably frightening themes introduced into pretend play are likely to result in play termination. Over time, young players learn these rules and develop a repertoire of behaviors that constitute the basis of coordinated, social play. Göncü (2017) describes these skills in terms of social imaginative play as intersubjective, that is, a shared endeavor - cognitively, emotionally, motivationally, and communicatively. This self-regulation of behavior in coordination with the needs and desires of others is one of the bases for successful social interactions in adulthood.

Play with ICs affords a wider array of social situations and experiences than typical play. For example, play fighting with a real partner requires a delicate balance of aggression and retreat, reciprocity of dominance, and reminders that the fighting is playful (Bekoff, 2001). In contrast, a child can imagine a conflict with an IC, engage in all manner of behaviors and manifestations of anger for as long as desired, and then either choose to engage in the complex process of conflict resolution or simply declare the conflict ended (without the negative relational implications that would be likely should a child choose this route with a real peer). A child who chooses the latter course of action might miss out on the benefits of learning and practicing conflict resolution skills, but the purpose of such play might relate to the experience and management of overwhelming negative emotions rather than social reconciliation per se. In this way, children's interactions with their ICs allow them to practice precisely the social skills they want to practice, and to avoid those they do not.

Although simulating a relationship with another being provides a context for practicing social skills that might be useful in adulthood, the fact that the play partner is not real in childIC play has implications for what might or might not be 
learned in this play. Specifically, juveniles of many species engaging in play learn the repertoire of behaviors needed to engage in and sustain social forms of play. Such behaviors include signals that acknowledge the context as play, such as bowing in canids (Bekoff, 1995) and frequent role reversals (attacker vs. defender) in rats (Pellis \& Pellis, 2007). Learning to provide and interpret such signals is part of the mutual coordination of behavior that theoretically provides practice for cooperation and reciprocity in relationships later in development (Durand \& Schank, 2015; Pellis \& Pellis, 2007).

Young human children engage in these signals of play just as dogs and rats do. Social pretense, for example, is marked for and by children through signals like smiles and looks and specific kinds of statements that define and describe the play (Farver, 1992; Lillard \& Witherington, 2004). In the case of ICs, however, children are engaging in a form of pretense that does not have to be signaled, as the play partner, as it were, does not exist. Instead, pretense involving an IC is a simulation of reality - including performance of behaviors that imitate real interactions without the necessity of signaling that it is play. In an odd way, then, this form of play lies somewhere between the practice in coordination of behaviors necessitated by other forms of play, and the practice in interpersonal skills available in interactions with real others. Instead of learning to signal, "This is play," children playing with ICs simulate actual interaction.

Simulation of interaction in the form of an IC turns out to be correlated with quite a few interpersonal skills. For example, in comparison to their peers, children with ICs have been found to be more sociable (Partington \& Grant, 1984), more cooperative (Singer \& Singer, 1990), and better at talking to and initiating activities with adults (Manosevitz et al., 1973). Some research finds advanced theory of mind among young children with ICs in comparison to their peers (Taylor \& Carlson, 1997) as well as a richness in the narratives they tell to others (Trionfi \& Reese, 2009) and in their understanding of what information another person needs in hearing a story (Roby \& Kidd, 2008). Again, teasing apart the causal relationships between these skills and the simulation of a social relationship has not been accomplished, and the significant number of children who do not create ICs and yet develop sophisticated social skills suggests that this phenomenon is but one pathway to successful, adaptive social functioning in adulthood.

The lack of signaling needed in play with ICs is not the only way in which it diverges from other forms of play. Contrary to many forms of play in several species, children frequently share their play with ICs with adults (i.e., parents) but not with other children (Gleason et al., 2000). Certainly, human adults and adults in other species (particularly primates) engage in play with juveniles (Pellis \& Iwaniuk, 1999), but the fact that children rarely share their ICs with children outside of their own families is unusual for play in humans. It raises the question of whether ICs are particular somehow to the social contexts in which they exist; that is, ICs might be useful or relevant in ways that relate more to the parent-child or family relationships than to the peer context. The psychological significance of play with ICs might thus be considered in terms of its effects on the real social context, particularly with reference to the child-parent relationship.

\section{Imaginary companions in the real social context}

The role of IC play in child-parent relationships is relevant given that children often discuss their ICs with parents (Newson \& Newson, 1968; Taylor, 1999). Not all children with ICs do so, of course (Taylor \& Carlson, 1997), but for those that do, these conversations might be particularly important. For one thing, parents who do know about their children's ICs report more talk about the ICs than with the ICs, particularly for children with invisible imaginary companions (Gleason \& White, 2005). In a sense, then, children's IC play occurs at least partly in the context of the parent-child relationship and might theoretically influence that relationship in significant ways. Specifically, children's IC play with parents affords opportunities to negotiate social roles, particularly within the family hierarchy as well as providing opportunity for psychological distance in handling emotionally charged situations.

\section{Negotiation of social roles}

A great deal of play is executed with attention to social roles and norms (Pellis \& Pellis, 2007). In the case of children and adults, especially parents, the relationship is well defined by its vertical nature, in that adults are more competent, skilled, and powerful than children, but also bear responsibility for the children's well-being. In cases in which both adults and children participate in play related to ICs, both parties must acknowledge the boundaries to their own roles in the play. To do so results in an interesting dynamic, because children are the authorities on their ICs' thoughts and actions (Klein, 1985). In contrast to most every other situation in the parent-child relationship, children are the experts regarding ICs, and the fact that the IC is entirely the child's creation must be respected. However, even in the context of play with or around a child's IC, the authority of the adult must be preserved. For example, if a child reports that the IC wants to misbehave, the parent is unlikely to acquiesce. According to examples in the literature, failure either to acknowledge the child's expertise on the IC or to maintain parental authority has negative consequences for the play.

Benson and Pryor (1973) describe an incident in which a well-meaning grandfather asked his granddaughter to have her 
invisible IC dog close his garage door. When she agreed, unbeknownst to her, the grandfather activated the automated door, surprising the girl. After this incident, the girl stopped talking about her imaginary dog. When questioned as to its whereabouts, she replied that she no longer played with the dog because it had to remain at her grandfather's house so as to operate the garage door. In a similar episode in a qualitative study, an adult's effort to make a child's personified object teddy bear dance resulted in the child grabbing the bear away from the adult, tossing it aside, and pushing the adult out the door. The child subsequently apologized to the bear, but not to the adult (Gleason \& White, 2005). In both of these instances, the adult's co-opting of the IC's actions changed the dynamics of the play. For the dog, IC play was ended; for the teddy bear, the child-IC relationship was preserved, but significant anger was expressed at the adult, and play was temporarily suspended.

Children often discuss their ICs in a way that attributes autonomy of thought and action to these creations (Taylor et al., 2007). In these instances, parents are rarely able to convince the child to simply imagine that the IC is behaving differently. For instance, Taylor (1999) reports one family's outing to a horse show. The mother specifically brought her 3year-old daughter, who had an imaginary pony, because of her interest in horses. However, the outing was ruined by the fact that child searched for her invisible pony to no avail- he wasn't there, and the girl was genuinely frustrated. The girl's mother could not convince her to pretend otherwise.

While children are the experts on their ICs, adults typically limit the use of the IC to subvert the hierarchy between children and parents in other contexts. For example, many children with ICs have tried placing blame for their own misbehavior onto their ICs at least once (Fraiberg, 1959; Gleason et al., 2000; Newson \& Newson, 1968; Taylor, 1999) Anecdotally, parents report children using ICs to delay bedtime or avoid other unpleasant activities, but these efforts are not usually successful. For instance, a child in one study told his father that the IC had made a rule that people wearing belts could not come in the child's room, meaning that the father would be unable to put the child to bed. The father's response was simply, "OK, let's go to bed" (Gleason \& White, 2005). By refusing to engage in conversation about the IC and its new rule, the father did not engage in the play and instead, asserted his authority.

Of course, children also engage their parents in play with the IC that is consistent with the hierarchical organization of the parent-child relationship. For example, parents are often asked to do things for the companion, such as buckle it in the car or set a place for it at the table (Benson \& Pryor, 1973; Stone \& Church, 1968). The extent to which parents are willing to indulge these requests can be interpreted as individual differences in the extent to which parents are willing to engage in this symbolic form of play as per their children's requests.

\section{ICs as a tool for psychological distance}

Play with ICs is a means of interpersonal communication, and children sometimes recognize the usefulness of the IC for communicating negative feelings (e.g., anger at the parent) indirectly. This displacement of negative emotion onto the IC is a form of psychological distancing - cognitively separating from the reality of the situation and representing it symbolically instead (Sigel, 1993). Theoretically, by attributing their own emotions to their ICs, children provide themselves with a way of detaching from an emotionally charged situation so as to examine it from a third-party perspective. Play with ICs, like pretend play, thus provides opportunities to selfregulate through abstraction into symbolism (Vygotsky, 1967). Such psychological distancing makes this play valuable as a tool for displacing overwhelming emotion - thus helping to preserve positive feelings within the reality of the parent-child relationship and maintain communication.

The ability to use imagination to obtain psychological distance in this manner has been positively related to children's ability to process emotionally charged information (Carlson \& Davis, 2005). It has also been positively related to children's executive function (White \& Carlson, 2016), a skill set including self-control and mental flexibility that has implications for successful functioning in relationships. The opportunity that ICs provide for creating psychological distance from the puzzles and emotions inherent in close relationships might allow for successful resolution of complex social issues. Such practice is particularly important for young children who are not yet capable of simultaneously engaging in complex relationship negotiations and regulating strong emotions. An interesting hypothesis is that the development of these skills and the ability to integrate them might be a factor accounting for the lower incidence of ICs as children age. If provision of psychological distance is a major function of play with ICs, then ICs might wane in their usefulness as social skills and selfregulation develop.

\section{Conclusions}

Consideration of the evolutionary and psychological significance of play with ICs makes clear that such behavior is not an evolutionary adaptation in and of itself. The mere fact that only some children create such friends, and yet most typically developing children master the social skills necessary for healthy relationships, suggests that ICs are not a determinant of evolutionary fitness. Instead, this form of play is likely a byproduct of two other adaptations that have conferred a significant advantage over the course of evolution. First, the evolution of imagination opened human cognition to all kinds of advantages in planning for the future and consideration of possible outcomes to various courses of action. Second, like 
other social mammals, humans have evolved neurobiological systems that promote the formation of social bonds. These attachments are shaped by processes in the earliest parentchild relationships, generalizing to later close relationships as well as basic affiliation with conspecifics - all bonds associated with health and well-being (Bowlby, 1979; Feldman, 2017). The combined capacities for imagination and relationship formation might be behind the development of ICs in play. Indeed, we might be surprised if, in play, human children did not occasionally exercise a valuable, complex cognitive skill like imagination in relation to their most pressing psychological concern - relationships with others.

Children's interactions with ICs and their interactions with others in relation to ICs suggest a psychological purpose to this play that is primarily social and largely symbolic. ICs are thus simultaneously unique to humans in their use of complex cognitive skills like imagination and fantasy, but consistent with play in other social animals in their emphasis on the centrality of interactions and relationships to the developmental process. The fact that children's relationships with their ICs reflect the social organization inherent in relationships with real others highlights the usefulness of this sort of play in the study of development and children's emerging understanding of social hierarchies and networks. At the same time, ICs emphasize the psychological significance of play in helping children learn to negotiate and manage social interactions and use symbolism as a tool for understanding their own and others' emotions and behavior. This extra practice, albeit imagined and only a simulation of reality, might help children develop the social skills and relationship-related cognitive abilities necessary for successful adaptation in adulthood.

\section{References}

Ames, L., \& Learned, J. (1946). Imaginary companions and related phenomena. Journal of Genetic Psychology, 69, 147-167.

Bekoff, M. (1995). Play signals as punctuation: The structure of social play in canids. Behaviour, 132, 419-429.

Bekoff, M. (2001). Social play behaviour: Cooperation, fairness, trust, and the evolution of morality. Journal of Consciousness Studies, 8, 81-90.

Benson, R., \& Pryor, D. (1973). When friends fall out: Developmental interference with the function of some imaginary companions. Journal of the American Psychoanalytic Association, 21, 457-473.

Bouldin, P., \& Pratt, C. (2002). A systematic assessment of the specific fears, anxiety level, and temperament of children with imaginary companions. Australian Journal of Psychology, 54, 79-85.

Bowlby, J. (1979). Attachment and loss (Vol. 1). New York: Basic Books.

Carlson, S., \& Davis, A. (2005). Executive function and pretense in preschool children. Paper presented at the annual meeting of the Jean Piaget Society, Vancouver, BC.

Carlson, S., \& Taylor, M. (2005). Imaginary companions and impersonated characters: Sex differences in children's fantasy play. MerrillPalmer Quarterly, 51, 93-118.
Connolly, J. A., \& Doyle, A. (1984). Relation of social fantasy play to social competence in preschoolers. Developmental Psychology, 20, 797-806.

Durand, S., \& Schank, J. C. (2015). The evolution of social play by learning to cooperate. Adaptive Behavior, 23, 340-353.

Farver, J. A. M. (1992). Communicating shared meaning in social pretend play. Early Child Research Quarterly, 7, 501-516.

Feldman, R. (2017). The neurobiology of human attachments. Trends in Cognitive Sciences, 21, 80-99.

Fraiberg, S. (1959). The magic years. New York: Charles Scribner's Sons.

Gleason, T. (2002). Social provisions of real and imaginary relationships in early childhood. Developmental Psychology, 38, 979-992.

Gleason, T. (2013). Imaginary relationships. In M. Taylor (Ed.), Handbook of the development of imagination (pp. 251-271). Oxford: Oxford University Press.

Gleason, T., \& Hohmann, L. (2006). Concepts of real and imaginary friendships in early childhood. Social Development, 15, 128-144.

Gleason, T., Jarudi, R., \& Cheek, J. M. (2003). Imagination, personality, and imaginary companions. Social Behavior and Personality: An International Journal, 31, 721-737.

Gleason, T., \& Kalpidou, M. (2014). Imaginary companions and young children's coping and competence. Social Development, 23, 820 839. doi: $10.1111 /$ sode. 12078

Gleason, T., Sebanc, A., \& Hartup, W. (2000). Imaginary companions of preschool children. Developmental Psychology, 36, 419-428.

Gleason, T., \& White, R. (2005, April). Talking to a tiger: Children's dayto-day interactions with their imaginary companions. Paper presented at the biennial meeting of the Society for Research in Child Development, Atlanta, GA.

Göncü, A. (2017). Constructing the ensemble: Negotiating life with (in) play. Manuscript submitted for publication.

Gopnik, A. (2002). Bumping into Mr. Ravioli: A theory of busyness, and its hero. New Yorker, 80-84

Hartup, W. W. (1983). Peer relations. In P. Mussen (Ed.), Handbook of child psychology (Vol. 4, 4th ed., pp. 103-196). New York, NY: Wiley.

Henricks, T. S. (2015). Play as experience. American Journal of Play, 8 , $18-49$.

Hoff, E. (2004-2005). A friend living inside me-The forms and functions of imaginary companions. Imagination, Cognition, and Personality, 24, 151-189.

Kastenbaum, R., \& Fox, L. (2007-2008). Do imaginary companions die? An exploratory study. Omega, 56, 123-152.

Kelley, H., Berscheid, E., Christensen, A., Harvey, J., Huston, T., Levinger, G.,...Peterson, D. (1983). Analyzing close relationships. In H. Kelley, E. Berscheid, A. Christensen, J. Harvey, T. Huston, G. Levinger,...D. Peterson (Eds.), Close relationships (pp. 20-67). New York, NY: W. H. Freeman.

Klein, B. (1985). A child's imaginary companion: A transitional self. Clinical Social Work Journal, 13, 272-282.

Lillard, A. S., Lerner, M. D., Hopkins, E. J., Dore, R. A., Smith, E. D., \& Palmquist, C. M. (2013). The impact of pretend play on children's development: A review of the evidence. Psychological Bulletin, 139, 1-34. doi:10.1037/a0029321

Lillard, A. S., \& Witherington, D. C. (2004). Mothers' behavior modifications during pretense and their possible signal value for toddlers. Developmental Psychology, 40, 95-113.

Manosevitz, M., Prentice, N., \& Wilson, F. (1973). Individual and family correlates of imaginary companions in preschool children. Developmental Psychology, 8, 72-79.

Masih, V. (1978). Imaginary play companions of children. In R. Weizman, R. Brown, P. Levinson, \& P. Taylor (Eds.), Piagetian theory and the helping professions (pp. 136-144). Los Angeles: University of Southern California Press.

Newson, E., \& Newson, J. L. (1968). London. UK: George Allen \& Unwin. 
Partington, J., \& Grant, C. (1984). Imaginary playmates and other useful fantasies. In P. Smith (Ed.), Play in animals and humans (pp. 217240). New York: Basil Blackwell.

Pearson, D., Rouse, H., Doswell, S., Ainsworth, C., Dawson, O., Simms, K.,...Falconbridge, J. (2001). Prevalence of imaginary companions in a normal child population. Child: Care, Health, and Development, 27, 13-22.

Pelligrini, A. (1992). Rough-and-tumble play and social problem solving flexibility. Creativity Research Journal, 5, 13-26.

Pellis, S. M., \& Iwaniuk, A. (1999). The problem of adult play fighting: A comparative analysis of play and courtship in primates. Ethology, 105, 783-806. doi:10.1046/j.1439-0310.1999.00457.x

Pellis, S. M., \& Pellis, V. C. (2007). Rough-and-tumble play and the development of the social brain. Current Directions in Psychological Science, 16, 95-98.

Roby, A. C., \& Kidd, E. (2008). The referential communication skills of children with imaginary companions. Developmental Science, 11, 531-540.

Shavel-Jessop, S., \& Segal, H. (2005, March). The imaginary companion and the isolated child: Anxiety, loneliness, and self-worth in children with imaginary companions. Paper presented at the biennial meetings of the Society for Research in Child Development, Atlanta, GA.

Sigel, I. E. (1993). The centrality of a distancing model for the development of representational competence. In R. R. Cocking \& K. A. Renninger (Eds.), The development and meaning of psychological distance (pp. 141-158). Hillsdale: Erlbaum.

Singer, D., \& Singer, J. (1990). The house of make believe. Cambridge: Harvard University Press.

Stone, L. J., \& Church, J. (1968). The preschool child: 1. New York: Random House.

Svendsen, M. (1934). Children's imaginary companions. Archives of Neurology and Psychiatry, 32, 985-999.

Taylor, M. (1999). Imaginary companions and the children who create them. New York: Oxford University Press.
Taylor, M., \& Carlson, S. (1997). The relation between individual differences in fantasy and theory of mind. Child Development, $68,436-455$.

Taylor, M., \& Carlson, S. (2002). Imaginary companions and elaborate fantasy in childhood: Discontinuity with nonhuman animals. In R. Mitchell (Ed.), Pretending and imagination in animals and children (pp. 167-180). Cambridge: Cambridge University Press.

Taylor, M., Carlson, S., Maring, B., Gerow, L., \& Charley, C. (2004). The characteristics and correlates of fantasy in school-age children: Imaginary companions, impersonation, and social understanding. Developmental Psychology, 40, 1173-1187.

Taylor, M., Carlson, S., \& Shawber, A. (2007). Autonomy and control in children's interactions with imaginary companions. Proceedings of the British Academy, 147, 81-100.

Taylor, M., Cartwright, B., \& Carlson, S. (1993). A developmental investigation of children's imaginary companions. Developmental Psychology, 29, 276-285.

Taylor, M., Hulette, A., \& Dishion, T. (2010). Longitudinal outcomes of young high-risk adolescents with imaginary companions. Developmental Psychology, 46, 1632-1636.

Taylor, M., \& Mottweiler, C. (2008). Imaginary companions: Pretending they are real, but knowing they are not. American Journal of Play, 1 , $47-54$.

Trionfi, G., \& Reese, E. (2009). A good story: Children with imaginary companions create richer narratives. Child Development, 80, 1301-1313.

Vygotsky, L. S. (1967). Play and its role in the mental development of the child. Soviet Psychology, 5, 6-18.

Weiss, R. (1974). The provisions of social relationships. In Z. Rubin (Ed.), Doing unto others (pp. 17-26). Englewood Cliffs: Prentice Hall.

White, R. E., \& Carlson, S. M. (2016). What would Batman do? Selfdistancing improves executive function in young children. Developmental Science, 19, 419-426. doi:10.1111/desc.12314 